\title{
INTERLEUKIN (IL) 12, IL-23 AND IL-23 RECEPTOR IN ANKYLOSING SPONDYLITIS PATHOPHYSIOLOGY
}

Marius Cherciu', Laura Ioana Cherciu', Mihai Bojinca², Teodora Serban², Constantin Bara1, Olivia Mihaela Popa ${ }^{1}$

${ }^{\prime}$ Department of Immunology and Pathophysiology, Faculty of Medicine, Carol Davila University of Medicine and Pharmacy, Bucharest

${ }^{2}$ Department of Rheumatology and Internal Medicine, Faculty of Medicine, Carol Davila University of Medicine and Pharmacy, I.C. Cantacuzino Hospital, Bucharest

\begin{abstract}
Ankylosing spondylitis (AS) is a chronic inflammatory arthritis which involves mainly the spine and the sacroiliac joints, but also the peripheral joints and nonarticular structures. IL-12 and IL-23 are heterodimeric cytokines sharing a common p40 subunit. Studies showed than IL-12 is essential for Th1 differentiation while IL-23 promotes a particular subset of T cells characterized by IL-17 production, called Th17. Since the association of IL-23R with AS was reported, the scientific interest has focused on identifying new single nucleotide polymorphisms (SNPs), present in the coding genes for IL-12/L-23 subunits and their receptors, that increase the susceptibility for AS. Another point of interest for researchers was to investigate if the identified gene variants modify the gene expression of the respective interleukins and/or their receptors, whether that refers to their mRNA expression, their serum levels or the expression of the receptors on the surface of T cells. Given the increasing amount of data that suggests the pivotal role of the IL-23/Th17 axis in AS pathophysiology, new promising therapies, designed to interfere with these pathways, are now in development.
\end{abstract}

Keywords: IL-12, IL-23, IL-23R, ankylosing spondylitis, single nucleotide polymorphisms (SNPs)

\section{INTRODUCTION}

Ankylosing spondylitis (AS) is a chronic inflammatory arthritis which involves mainly the spine and the sacroiliac joints and, to a lesser extent, the peripheral joints and nonarticular structures. Along with psoriatic arthritis (PsA), reactive arthritis $(\operatorname{ReA})$, arthritis associated with inflammatory bowel disease and undifferentiated spondyloarthritis (uSpA), AS belongs to the family of spondyloarthritis ( $\mathrm{SpA})(1)$ which are characterized by common clinical features like inflammatory back pain, peripheral asymmetrical oligoarthritis, enthesitis and extra-articular manifestations (uveitis, dactylitis, psoriasis or chronic inflammatory bowel disease) and genetic similarities (2-4).

The genetic heritage of AS is undisputed. Today, more than $90 \%$ of the risk to develop this disease is considered to be genetically determined $(5,6)$. Although the association with HLA-B27 has been well documented since 1973 (7), only in recent years, genome wide association studies (GWAS) have identified new genes outside the major histocompatibility complex (IL-1 gene cluster, $I L-23 R$ and ERAPI) which were proven to affect the susceptibility to AS $(8,9)$, opening new perspectives in understanding the intimate pathophysiological mechanisms not only of AS, but also of other SpA.

\section{IL-12, IL-23 CHARACTERISTICS (STRUCTURE, RECEPTORS, SIGNALING)}

IL-12 (p70) is a disulfide-linked heterodimeric cytokine composed of two subunits: p35 and p40. Each subunit is encoded by a different gene: $I L-12 \mathrm{~A}$ located on chromosome 3q25.33 encodes p35 sub-

Correspondence address:

Olivia Mihaela Popa, PhD, Carol Davila University of Medicine and Pharmacy, 37 Dionisie Lupu Street, Bucharest

E-mail: oliviapopa@yahoo.com 
unit and $I L-12 B$ located on chromosome $5 \mathrm{q} 31.1-$ q33.1 encodes p40 subunit. Consequentially, IL-12 receptor $(\mathrm{R})$ has two subunits as well: IL-12R $\beta 1$ for p40 subunit and IL-12R 32 for p35 subunit (see Table 1). After binding the high-affinity receptor complex, IL-12 gathers together the closely related subunits and triggers the intracellular signaling via Janus kinase 2 (JAK2) and tyrosine kinase 2 (TYK2), subsequently activating through phosphorylation the signal transducer and activator of transcription (STAT) 4 (10-12). Synthetized by antigen-presenting cells (APC) like dendritic cells and macrophages exposed to pathogenic molecules that bind to tolllike receptors (TLRs), IL-12 induces the differentiation of naive CD4+ T cells into IFN- $\gamma$-producing Thelper (Th)1 cells (13-15), being the central cytokine in generating Th1 cells and thus playing a major role in mediating the cellular immunity $(16,17)$.

TABLE 1. Characteristics of IL-12 and IL-23

\begin{tabular}{|l|l|l|}
\hline & IL-12 & IL-23 \\
\hline Subunits & p35/p40 & p40/p19 \\
\hline Genes & IL-12A/IL-12B & IL-12B/IL-23A \\
\hline Receptors & IL-12Rb2/IL-12Rb1 & IL-12Rb1/IL-23R \\
\hline STAT & STAT4 & STAT3 \\
\hline
\end{tabular}

IL-23 was identified more than 10 years after IL-12, in 2000 by Dr. Kastelein's group (DNAX Research Institute, Palo Alto, CA) and it shares struc- tural and functional similarities with IL-12 (12) as it is part of the IL-6/IL-12 family. A heterodimeric cytokine as well, IL-23 presents the same p40 subunit which this time is covalently bound with p19 subunit, a four $\alpha$ helix cytokine p35-related protein (12). Located on chromosome 12q13.3, the gene encoding this subunit is called $I L-23 A$. IL-23 receptor presents the same IL-12R subunit IL-12R $\beta 1$ (receptor for $\mathrm{p} 40$ ) and a novel subunit called IL-23R which is the receptor for p19 subunit (18) (Fig. 1). The $I L-23 R$ gene is located on the short (p) arm of chromosome 1 at position 31.3. IL-23R is present on the membrane of T cells and natural killer (NK) cells.

Secondary to the IL-23 recognition, the two receptorial subunits (IL-12R $\beta 1$ and IL-23R) suffer conformational changes that do not follow the classical "site I-II-III" architectural paradigm (19). A cascade of intracellular events follows: IL-23R is tyrosine-phosphorylated and JAK2 and STAT3 couple with IL-23R, the later in a ligand dependent manner, while IL-12R $\beta 1$ is connected with TYK2 (18). As a result, a series of JAK-STAT signaling molecules are activated: TYK2, JAK2, and STAT1, $-3,-4$, and -5 , somewhat similar with the response to IL-12. Only that, in contrast to IL-12, STAT3 is the most important STAT activated by IL-23 rather than STAT4, therefore different DNA-binding STAT transcription factor complexes are formed as a response to IL-23 compared with IL-12 (18).

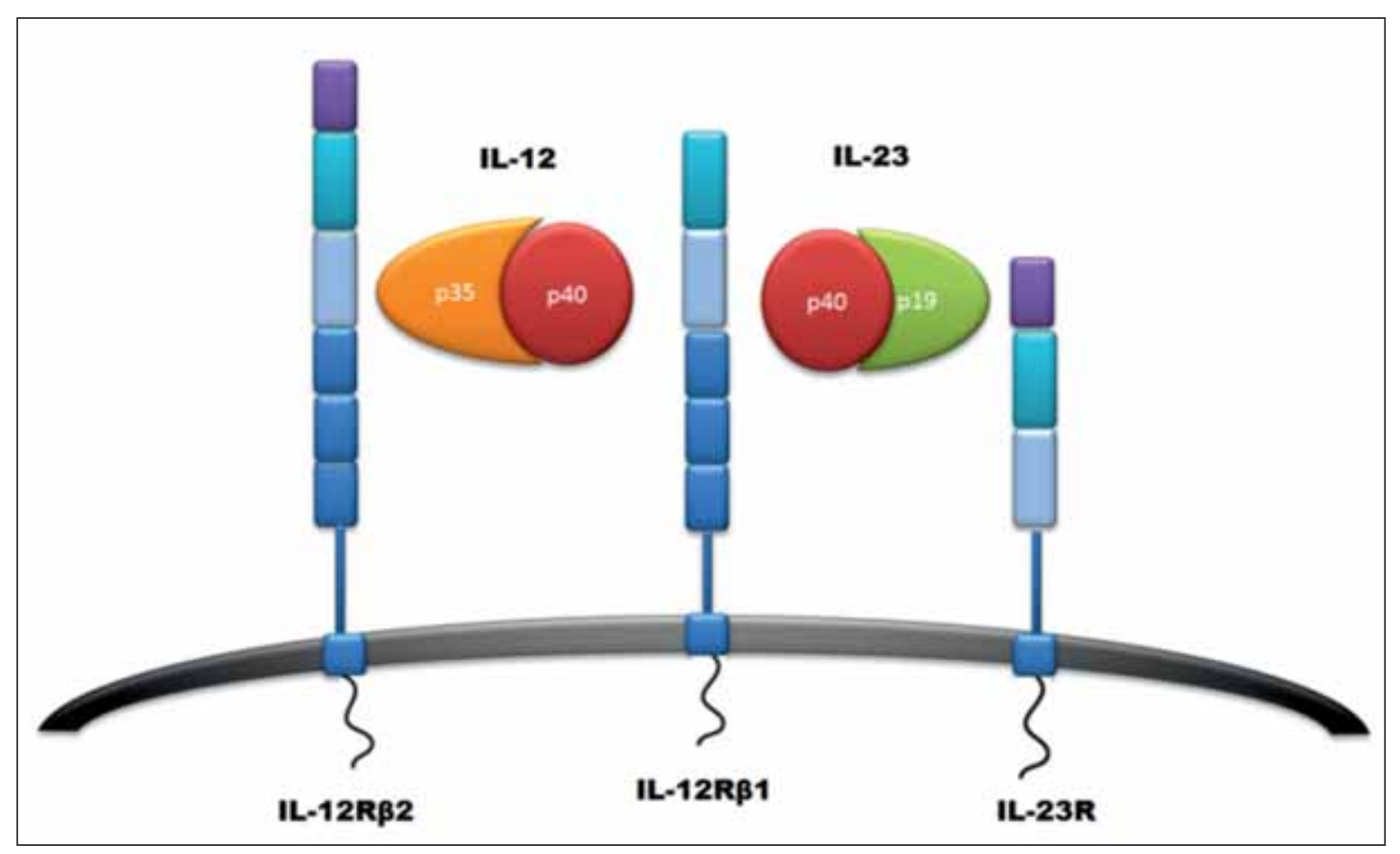

FIGURE 1. IL-12, IL-23 and their receptors 
The biological responses to these similar interleukins are significantly different, together regulating Th1 cells development. As mentioned before, IL-12 acts on naive Th, while IL-23 activates the memory T cells (12) but also NK cells. It was demonstrated that IFN- $\gamma$ production is greatly enhanced in response to IL-23 and that polyclonal antibodies anti-IL-23R and anti-IL-12R $\beta 1$ inhibit IFN- $\gamma$ production (20). Moreover, IL-23 activates phosphoinositide-3-kinase (PI3K)/RAC-alphaserine/threonine kinase (AKT) and nuclear factor kappa $\mathrm{B}(\mathrm{NF}-\mathrm{kB})$ pathways involved in IL-17 production (20).

Studying the implication of these findings in relation with the development of autoimmune diseases showed that IL-23 has a greater influence than IL-12 (21), by promoting a particular subset of $\mathrm{T}$ cells characterized by production of IL-17 (22-24).

IL-23 is synthetized by APC, mainly activated dendritic cells, monocytes and macrophages, following the recognition of the microbial biochemical structures via TLRs. As a result a distinct immune response is promoted, which leads to Th17 cell differentiation (25). Although IL-23 is involved also in Th1 cells differentiation following increased IFN- $\gamma$ production, it is now widely accepted that IL-23 main role is in generating a CD4+ helper T-cell subset characterized by the production of IL-17, tumor necrosis factor, IL-8 and IL-6, known as Th17 cells, and has a major role in the pathogenesis of autoimmune diseases $(26,27)$.

Studies using gene-targeted mice showed an increase susceptibility of the mice lacking IL-12p35 and IL-12R $\beta 2$ to experimental autoimmune encephalomyelitis and collagen-induced arthritis $(23,28)$, while mice deficient for IL-23p19, p40 or IL-12R $\beta 1$ were resistant in developing any joint or bone pathology (23). This apparently paradoxical response is correlated with the IL-17 production which is stimulated by IL-23 and suppressed by IL-12. These studies confirm IL-23 as a determinant factor of joint autoimmune inflammation (via IL-17-producing $\mathrm{CD}^{+} \mathrm{T}$ cells) whereas IL-12 has a protective role $(23,28)$.

\section{IL-23R GENE VARIANTS ASSOCIATED WITH AS}

Since 2007, when the Welcome Trust Case Control Consortium and the Australo-Anglo-American Spondyloarthritis Consortium GWAS reported the association of IL-23R with AS (9), the scientific in- terest has focused on identifying new single nucleotide polymorphisms (SNPs) present in the coding genes for IL-12/IL-23 subunits and their receptors that increase the susceptibility not only for AS, but also for other SpA.

In 2010 the same consortium replicated the $I L-23 R$ rs 11209026 association with AS analyzing more than 2000 AS cases and more than 5000 controls among people of European descent (8).

A growing number of replication studies in various populations investigating various SNPs emerged. In a case-control study in the UK population, Karaderi et al identified seven $I L-23 R$ SNPs associated with AS, rs11209032 and rs11209026 presenting the strongest correlation (29). The examination of three cohorts of AS patients from Canada, revealed that $I L-23 R$ SNPs rs 10489629, rs2201841 and rs11465804 increase the susceptibility for AS while the minor allele A of the nonsynonymous SNP rs11209026 (Arg$381 \mathrm{Gln}$ ) proved to be protective against AS (30).

In an interesting genotype/phenotype correlation approach, rs 11209026 was investigated in a French cohort, showing not only the association of the $I L-23 R$ SNP with the AS susceptibility, but also that both radiographic sacroiliitis and early age onset were associated with a low frequency of the protective minor allele A, suggesting an involvement in disease severity as well (31).

The previously mentioned non-synonymous rs11209026 (Arg381Gln) along with rs1343151 was found to offer susceptibility to AS in a Spanish population (32), while the analysis of a Portuguese population showed the association of another $I L-23 R$ SNP (rs1004819) with AS, although no association with the clinical manifestations was seen (33).

Investigating the $I L-23 R$ gene haplotype variants in a Hungarian population, Szabo et al identified a number of SNPs (rs1004819, rs2201841, rs10889677, rs1343151) associated not only with AS, but also with Crohn's disease (CD), while other SNPs (rs2201841 and rs10889677) showed susceptibility for rheumatoid arthritis (34). Another study in a Hungarian population found similar $I L-23$ gene variants (rs11805303, rs1004189) associated with AS but not with Sjögren syndrome (35).

Although the studies in European and North American populations and two meta-analysis $(36,37)$ show unanimous consensus about the association of $I L-23 R$ SNPs with AS, these findings are yet to be confirmed in Asian populations. No association was found between IL-23R gene variants (ten SNPs were 
investigated) and AS in a Korean population (38). In Han Chinese populations, Davidson et al. did not replicate the association of rs11209026 with AS (widely regarded as the most important AS-associated SNP in Europeans) because it was nonpolymorphic, potentially explaining the lack of association in this ethnic group (39), and neither Qian et al. for rs1004819 and rs10889677 (40). A meta-analysis from 2012 found no evidence of association between any SNPs belonging to $I L-23 R$ gene and AS in East Asian population (41). Although it seems that AS pathogenesis may not implicate IL-23R in Asians, more recent studies showed some uncommon $I L-23 R$ gene variants that do confer susceptibility to AS in Han Chinese population: the nonsynonymous SNP rs76418789 (Gly149Arg) (42) or rs17375018 which was associated with HLA-B27 positive AS and uveitis (43); similarly a study from 2010 found significant differences in the genotypes of rs11209032 and the differences in the genotypes and allele frequencies of rs6677188 between cases and controls, as well as elevated levels of IL-23R mRNA in Chinese patients with AS (44).

$I L-23 R$ gene polymorphisms seem to influence not only the risk of developing AS, but also the risk for other SpA (PsA, arthritis associated with inflammatory bowel disease), which presumably have similar etiopathogenic pathways involving IL-23/Th17 axis. Thus, several GWASs identified IL-23R as an inflammatory bowel disease gene (45) and as a psoriasis-risk gene $(46,47)$ and it was later confirmed in replication studies in several European, North American and Canadian populations (48-52).

The basis for the protective effect against AS, Crohn's disease or PsA of IL-23R Arg381Gln gene variant (rs11209026 - protective (A) allele) mentioned earlier and proven in many studies in different populations, seems to be the impairing IL-23-induced Th17 effector response without interfering necessarily with Th17 differentiation process. Di Meglio et al. showed that, although $I L-23 R$ Arg$381 \mathrm{Gln}$ gene variant did not influenced Th17 cell differentiation, both carriers of the $I L-23 R$ protective (A) and common $(\mathrm{G})$ allele having similar frequencies of circulating Th17 cells, the effector function of the IL-23-mediated Th17 cells was impaired, as Th17 cells from A allele carriers had significantly reduced IL-23-induced IL-17A production and STAT3 phosphorylation compared to $\mathrm{G}$ allele carriers (53).

Not as many studies focused on $I L-12 A, I L-12 B$ or IL-23A in AS. A Taiwanese study which enrolled more than 350 patients with AS shows that carriers of rs3212227 CC genotype belonging to $I L-12 B$ gene not only have a greater risk of developing AS, but also the severity of the disease, assessed with Bath Ankylosing Spondylitis Disease Activity Index (BASDAI), is higher (4.3 vs 3.7 score) when compared with AS patients carriers of AA genotype (54). But this study seems to be singular in AS, as most of them are investigating $I L-12 A, I L-12 B$ or $I L-23 A$ and their receptors (with the exception of $I L-23 R$ ) in psoriasis (PS) and PsA.

\section{IL-12, IL-23 SERUM LEVELS AND GENE EXPRESSION IN AS}

Another point of interest for researchers in studying the implications of IL-12, IL-23 and IL-23R in $\mathrm{AS}$ was to investigate if the gene variants, which associate with AS and other SpA, modify the gene expression of the respective interleukins and/or their receptors, whether that refers to their serum levels, their mRNA expression or the expression of the receptors of such interleukins on the cellular surface of the T lymphocytes. Although the vast majority of the studies confirmed elevated serum levels of IL-12 and IL-23 in AS and SpA patients, the result are conflicting when it comes to their association with the disease activity or the anti TNF treatment, as we will detail further.

A small study, which included just 17 AS patients, 8 PsA patients and 9 patients with rheumatoid arthritis along with 20 healthy control determined and compared IL-23R expression in T cells in each subject group and showed, for the first time, increased levels of IL-23R expression in the peripheral blood of AS patients. The percentage of IL-23R-expressing $\mathrm{T}$ cells in the periphery was two times higher in AS patients than in healthy controls, specifically driven by a 3 -fold increase in IL-23R-positive $\gamma / \delta \mathrm{T}$ cells in AS patients as well as enhanced IL-17 secretion in this group, providing a potentially pathogenic role of these cells in AS (55). The $\gamma / \delta$ T cells belong to the intraepithelial lymphocytes abundant in the gut mucosa which present characteristics that place them both in the innate and the adaptive immune system (56).

Trying to evaluate Th17 axis in AS patients, Taylan et al. measured the serum levels of IL-23 and IL-12, but also TGF- $\beta$, IL-17A and IL-6 in 127 AS patients and 38 controls. Although the cytokines levels were significantly higher in AS patients versus 
controls $(\mathrm{P}<0.05)$, within the AS group the cytokines levels didn't correlate with the disease activity and the anti-TNF treatment (57). Similarly, another group analyzed the serum levels of IL-17 and IL-23 in $50 \mathrm{AS}$ patients and 43 healthy controls. The serum IL-17 and IL-23 levels were significantly elevated in AS patients versus controls, but no association between the cytokines serum levels and disease activity was found (58). The same pattern repeated in a study which investigated IL-23, IL-17A and IL-21, and their association with disease activity and magnetic resonance imaging (MRI) findings in 80 patients with SpA (not only AS). Although the researchers did find a statistically significance difference between SpA patients and controls in the plasma levels of IL-23 and IL-21 (but not IL-17A), no association between these cytokines levels and MRI changes, and disease activity measured by BASDAI and Bath Ankylosing Spondylitis Functional Index (BASFI) were observed (59)

Investigating the expression not only of IL-23 and IL-17 in the serum and supernatants of cultured peripheral blood mononuclear cells (PBMCs) but also of IL-23p19 mRNA expression in PBMCs in AS patients, one study reported that patients with active AS (BASDAI > 4) present elevated levels of IL-23 and IL-17 in both serum and supernatants as well as a higher expression of IL-23p19 mRNA. An enhanced production of IL-17 in the supernatants of cultured PBMCs was found in the presence of recombinant IL-23, more significantly in the AS group, underlying the role of IL-23 and IL-17 in the pathogenesis of AS and that the IL-23-stimulated production of IL-17 in mononuclear cells may be responsible for the development of AS (60). Confirming these findings, another study involving Chinese patients showed significantly higher IL-23 and IL-17 levels in AS patients than in healthy controls, levels which correlated with disease activity measured by BASDAI score but not by BASFI and Bath Ankylosing Spondylitis Patient Global Score (BAS-G)(61).

A larger study, focusing on the response to antiTNF- $\alpha$ therapy in AS, which involved 222 AS patients, determined the frequencies of circulating Th17 cells, regulatory T cells (Tregs) and serum levels of IL-23, IL-17, IL- 6 and TNF- $\alpha$. The levels of IL-23, IL-17, IL-6 and TNF- $\alpha$ were significantly lower in responders while IL-23 and IL-17 were significantly elevated in non-responders. The frequency of circulating Th17 cells significantly decreased in responders and increased in non-responders while Tregs behaved in the opposite manner. The frequencies of Th17 cells and the levels of IL-23, IL-17 and TNF- $\alpha$ were positively correlated with BASDAI and BASFI. Thus, these results suggest that anti-TNF- $\alpha$ therapy in AS blocks not only TNF- $\alpha$, but also downregulates Th17 and Th17-related cytokines by upregulating the Treg/TGF- $\beta$ axis (62).

Wendling et al. assessed the serum and synovial levels of p40,common to IL-12 and IL-23, in $27 \mathrm{SpA}$ patients and 24 controls. But contrary to the previous studies, they found no statistical difference in serum levels of p40 between patients and controls, or between patients with axial and peripheral involvement. The $\mathrm{p} 40$ serum values did not correlate with the activity of the disease (BASDAI) or with standard inflammation markers (ESR, CRP). Moreover, the p40 serum levels didn't change after the patients were treated with TNF blockers, whereas significant reduction in BASDAI, ESR, and CRP were observed. Although higher mean synovial levels of p40 in $\mathrm{SpA}$ patients compared with controls were present, they concluded that $\mathrm{p} 40$ is not an adequate biologic tool of disease activity assessment in SpA patients (63).

Our personal unpublished observations seem to be similar. We determined the serum level of IL-12/ IL-23p40 common subunit in 21 AS patients and 20 healthy controls using a colorimetric sandwich ELISA kit, and we found no significantly statistical difference in the serum level of p40 between the two groups.

Following the possible involvement of IL-12 and IL-23 in AS pathogenesis, one study investigated the frequency of IL-23-positive and IL-12-positive cells within the subchondral bone marrow and within fibrous tissue replacing normal bone marrow determined by immunohistochemistry (double staining of CD163+ macrophages, CD68+ macrophages, $\mathrm{CD} 1 \mathrm{a}+$ dendritic cells, tryptase-positive mast cells, myeloperoxidase-positive cells, CD20+ B cells and CD3 + T cells) and found that IL-23-positive cells are more frequent in subchondral bone marrow from the joints of AS patients compared with osteoarthritis patients and controls, and therefore a potential therapeutic target in this disease (64).

Another group designed an interesting study, stimulating monocyte-derived dendritic cells (moDC) obtained from peripheral blood of patients with rheumatoid arthritis (RA) and AS with ligands for 
several Toll-like receptors and analyzed mRNA expression and cytokine secretion. Synergistic secretion of both IL-23 and IL-12p70 in all subjects was observed, but while IL-12p70 secretion did not differ between the two cohorts, IL-23 secretion by moDC was significantly higher in AS patients versus RA patients underlying the importance of this cytokine known for the major role played in differentiation of IL-17-secreting CD4+ Th17 cells in AS pathogenesis. TNF- $\alpha$, IL- 6 , and IL-10 were secreted at comparable levels in all subjects the same as the levels of mRNA in moDC for both IL-23p19 and IL12p35 subunits (65).

Ciccia et al. investigated the immunologic abnormalities underlying the subclinical intestinal inflammation in AS and CD and discovered a strong and significant up-regulation of IL-23p19 transcripts in the terminal ileum, produced there by the infiltrating monocyte-like cells in inflamed mucosa and Paneth cells, in both groups of patients when compared to controls. In AS patients though, IL-23 was not associated with up-regulation of IL-17 and the IL-17-inducing cytokines IL-6 and IL-1beta nor with IL12 p35 and IL-27p28 as it was in CD patients (66). This seems to indicate that IL-23 is an essential regulator of gut mucosal immunity, providing a convincing pathophysiologic insight to the reported association between IL-23R polymorphisms and intestinal inflammation.

Another line of enquiry was taken by an American group of researchers who wanted to determine whether macrophages from AS patients undergo an unfolded protein response (UPR) and increase the cytokines secretion in response to lipopolysaccharide (LPS). They differentiated in vitro PBMCs with macrophage colony-stimulating factor and then treated the samples with IFN $\gamma$ to up-regulate HLA-B expression prior to stimulation with LPS. A noticeable difference was observed as AS macrophages secreted more IL-23 (median $265 \mathrm{pg} / \mathrm{ml}$ in AS patients versus $9 \mathrm{pg} / \mathrm{ml}$ in controls; $\mathrm{P}=0.0007$ ), IL12p70, IL-10, CXCL9 and TNF $\alpha$ than control macrophages providing a logical support for developing IL-23 directed drugs. Contrary to previous studies of the HLA-B27-transgenic rat model of AS (67), no significant UPR induction was detected in AS patients which led them to believe that the relationship between UPR and inflammatory cytokine production remains unclear (68).

\section{NEW THERAPIES THAT TARGET THE IL-23/TH17 AXIS}

In the recent years, TNF blockers have become a standard therapy not only for AS but also for other SpA (PsA, CD). As we mentioned above, TNF blockers affect not only the TNF $\alpha$ molecule, but also IL-23 and Th17 cells in patients that have a positive response to the treatment (62). Given the increasing amount of data that suggests the pivotal role of the IL-23/Th17 axis in AS/SpA pathophysiology, including the greater production of IL-23 by AS patient macrophages in response to LPS (68), it was to be expected that the next logical step in the search for a new therapy, would be the development of new drugs which interfere with these pathways. The Th17/IL-23-directed therapy is now a promising new target in the treatment of SpA and AS (69-72).

Most of the new treatments are monoclonal antibodies that target these specific cytokines. One of the first molecule tested was ustekinumab (a monoclonal antibody directed against the common p40 subunit of IL-23 and IL-12) which, after proving to be efficient in moderate to severe psoriasis, it was approved in September 2013 by the US Food and Drug Administration (USFDA) for the treatment of PsA. A phase II clinical trial tested ustekinumab for the treatment of patients with active AS (TOPAS) and showed a significant reduction of signs and symptoms of AS correlated with reduction of active inflammation on MRI and of serum $\mathrm{C}$ reactive protein level (73). Another monoclonal antibody directed against the common p40 subunit of IL-23 and IL-12 is briakinumab but although the clinical trials for the treatment of psoriasis showed a positive impact on health-related quality of life, the manufacturer has withdrawn the application for this disease in the EU and US (74).

Guselkumab, a monoclonal antibody targeting the 19 submit, thus designed to block IL-23, but not IL-12, presented excellent results in phase II clinical trials for plaque psoriasis (http://www.medpagetoday.com/Dermatology/Psoriasis/44889) and may be a potential candidate for PsA and AS. Tildrakizumab is also anti-IL-23p19 monoclonal antibody and therefore designed to selectively block IL-23, which in clinical studies for the treatment of chronic plaque psoriasis, demonstrated efficacy, other potential future indications being PsA and CD (http://www.mercknewsroom.com/news-release/corporate-news/ 
sun-pharma-and-merck-co-inc-enter-licensingagreement-tildrakizumab).

Secukinumab, a human monoclonal antibody directed against IL-17A is investigated now in a number of chronic inflammatory disorders including AS. In a small phase II study in AS it showed promising results (75) confirmed by the larger phase III trial where more than $60 \%$ of patients achieved significant improvements in AS symptoms sustained through one year of treatment (76). In December 2014 it received its first global approval in Japan for the treatment of psoriasis and psoriatic arthritis in adults who are not adequately responding to systemic therapies (except for biologic agents). In the USA and the EU, secukinumab was approved in early 2015 for the treatment of patients with moderate-to-severe plaque psoriasis (77).

Ixekizumab and perakizumab (both monoclonal antibodies directed against IL-17A) and brodalumab (a monoclonal antibody against the IL-17RA receptor), have been recently used in phase II and III clinical trials in psoriasis, psoriatic arthritis and other subforms of SpA, with overall promising clinical efficacy (72). A list with the new potential therapeutic monoclonal antibodies in AS and SpA is found in Table 2.

TABLE 2. Novel monoclonal antibodies that target the IL-23/Th17 axis

\begin{tabular}{|l|l|}
\hline Monoclonal antibody & Target molecule \\
\hline Ustekinumab & IL-12/IL-23p40 \\
\hline Briakinumab & IL-12/IL-23p40 \\
\hline Guselkumab & IL-23p19 \\
\hline Tildrakizumab & IL-23p19 \\
\hline Secukinumab & IL-17A \\
\hline Ixekizumab & IL-17A \\
\hline Perakizumab & IL-17A \\
\hline
\end{tabular}

Most experts now agree that the new therapies should be beneficial to those patients nonresponsive to TNF $\alpha$ inhibitors, and should also focus on preventing and stopping the formation of syndesmophytes (78).

\section{CONCLUSIONS}

All the data presented constitute enough evidence to affirm that one of the mechanisms of chronic inflammation in AS and SpA implicates IL-23 (more than IL-12) and its receptor IL-23R. IL-23 signalling is essential for the differentiation of CD4+ Th17 cells (79) and for IL-17 production from $\gamma / \delta$ T cells (80) which later enhance the function of Th17 cells (81). The altered response to IL-23 signals mediated by IL-23R in $\gamma / \delta \mathrm{T}$ cells generates elevated IL-17 secretion, potentially explaining how the genetic association with IL-23R might operate in AS (55). Taking in consideration the fact that $\gamma / \delta \mathrm{T}$ cells are intraepithelial lymphocytes abundant in the gut mucosa and the known association of AS with antigen processing (ERAPI) and antigen presentation (HLA$B 27)$ genes, the ubiquitous pathogens exposure hypothesis as a potential pathogenic mechanism in AS may be one of the strongest candidate yet.

The most constantly reproduced IL-23R genetic association with AS (rs11209026 Arg381Gln) showed defective IL-23 signaling in Th17 cells from individuals carrying the protective A allele with significantly reduced IL-17A production compared with the individuals carrying the $\mathrm{G}$ allele, possible having a real impact in disease etiopathogeny and phenotype (53). Future studies should focus on discovering the functional impact of such disease associated gene variants as well as the impact on the therapeutic response, especially for the IL-23/Th17 directed therapy, some researchers suggesting that the IL-23R Arg381Gln polymorphism could be used as a genetic biomarker to predict the therapeutic response (53).

Although the current research provides us sometimes with conflicting results, and the journey from gene to function is not always an easy one, it seems that the intimate understanding of AS etiopathogenesis is closer than ever. This is not just a futile academic endeavor, but it provides us with the tools necessary to explore the phenotypic spectrum of the disease, and it is the only key to discovering, improving and personalizing the new therapeutic choices we will have for our patients.

\section{Acknowledgement}

Olivia M. Popa was supported by the Sectorial Operational Programme Human Resources Development (SOP HRD), financed from the European Social Fund and by the Romanian Government under the contract number SOP HRD/159/1.5/S/135760. 


\section{REFERENCES}

1. Zochling J., Brandt J., Braun J. The current concept of spondyloarthritis with special emphasis on undifferentiated spondyloarthritis. Rheumatology. 2005; 44(12):1483-91.

2. Zochling J., Smith E.U. Seronegative spondyloarthritis. Best Pract Res Clin Rheumatol. 2010; 24(6):747-56.

3. Braun J., Sieper J. [Spondyloarthritides]. Z Rheumatol. 2010; 69(5):425-32.

4. Landewe R.B., van der Heijde D.M. [The recognition of patients with spondyloarthritis. New classification criteria]. Ned Tijdschr Geneeskd. 2011;155(30-31).

5. Brown M.A. Breakthroughs in genetic studies of ankylosing spondylitis. Rheumatology. 2008; 47(2):132-7.

6. Reveille J.D. The genetic basis of ankylosing spondylitis. Current opinion in rheumatology. 2006; 18(4):332-41.

7. Brewerton D.A., Hart F.D., Nicholls A., Caffrey M., James D.C., Sturrock R.D. Ankylosing spondylitis and HL-A 27. Lancet. 1973; 1(7809):904-7.

8. The Australo-Anglo-American Spondyloarthritis Consortium (TASC) The Australo-Anglo-American Spondyloarthritis Consortium (TASC), Reveille JD, Sims AM, Danoy P, Evans DM, Leo P, et al. Genome-wide association study of ankylosing spondylitis identifies non-MHC susceptibility loci. Nat Genet. 2010; 42(2):123-7.

9. Burton P.R. C.D., Cardon L.R., Craddock N., Deloukas P., Duncanson A., et al. For The Australo-Anglo-American Spondylitis Consortium (TASC). Association scan of 14,500 nonsynonymous SNPs in four diseases identifies autoimmunity variants. Nat Genet. 2007; 39(11):1329-37.

10. Yoshimoto T., Furuhata M., Kamiya S., Hisada M., Miyaji H., Magami Y., et al. Positive modulation of IL-12 signaling by sphingosine kinase 2 associating with the IL-12 receptor beta 1 cytoplasmic region. J Immunol. 2003; 171(3):1352-9.

11. van de Vosse E., Lichtenauer-Kaligis E.G., van Dissel J.T., Ottenhoff T.H. Genetic variations in the interleukin-12/ interleukin-23 receptor (beta1) chain, and implications for IL-12 and IL-23 receptor structure and function. Immunogenetics. 2003; 54(12):817-29.

12. Oppmann B., Lesley R., Blom B., Timans J.C., Xu Y., Hunte B., et al. Novel p19 Protein Engages IL-12p40 to Form a Cytokine, IL23, with Biological Activities Similar as Well as Distinct from IL-12. Immunity. 2000;13(5):715-25.

13. Trinchieri G., Scott P. Interleukin-12: basic principles and clinical applications. Curr Top Microbiol Immunol. 1999;238:57-78.

14. Murphy K.M., Ouyang W., Farrar J.D., Yang J., Ranganath S., Asnagli H., et al. Signaling and transcription in T helper development. Annu Rev Immunol. 2000; 18:451-94.

15. O‘Garra A., Arai N. The molecular basis of T helper 1 and $T$ helper 2 cell differentiation. Trends in cell biology. 2000; 10(12):542-50.

16. Trinchieri G. Interleukin-12: a proinflammatory cytokine with immunoregulatory functions that bridge innate resistance and antigenspecific adaptive immunity. Annu Rev Immunol. 1995; 13:251-76.

17. Gately M.K., Renzetti L.M., Magram J., Stern A.S., Adorini L., Gubler U., et al. The interleukin-12/interleukin-12-receptor system: role in normal and pathologic immune responses. Annu Rev Immunol. 1998; 16:495-521.

18. Parham C., Chirica M., Timans J., Vaisberg E., Travis M., Cheung J., et al. A receptor for the heterodimeric cytokine IL-23 is composed of IL-12Rbeta1 and a novel cytokine receptor subunit, IL-23R. J Immunol. 2002; 168(11):5699-708.

19. Schroder J., Moll J.M., Baran P., Grotzinger J., Scheller J., Floss D.M. Non-Canonical Interleukin 23 Receptor Complex Assembly: P40 Protein recruits interleukin 12 receptor beta1 via site II and induces P19/Interleukin 23 receptor interaction via site III. The Journal of biological chemistry. 2015; 290(1):359-70.

20. Cho M.L., Kang J.W., Moon Y.M., Nam H.J., Jhun J.Y., Heo S.B., et al. STAT3 and NF-kappaB signal pathway is required for IL-23-mediated IL-17 production in spontaneous arthritis animal model IL-1 receptor antagonist-deficient mice. J Immunol. 2006; 176(9):5652-61.

21. Cua D.J. Interleukin-23 rather than interleukin-12 is the critical cytokine for autoimmune inflammation of the brain. Nature. 2003; 421:744-8

22. Aggarwal S., Ghilardi N., Xie M.H., de Sauvage F.J., Gurney A.L. Interleukin-23 promotes a distinct CD4 T cell activation state characterized by the production of interleukin-17. The Journal of biological chemistry. 2003; 278(3):1910-4.
23. Murphy C.A., Langrish C.L., Chen Y., Blumenschein W., McClanahan T., Kastelein R.A., et al. Divergent pro- and antiinflammatory roles for IL-23 and IL-12 in joint autoimmune inflammation. The Journal of experimental medicine. 2003; 198(12):1951-7.

24. Langrish C.L., Chen Y., Blumenschein W.M., Mattson J., Basham B., Sedgwick J.D., et al. IL-23 drives a pathogenic T cell population that induces autoimmune inflammation. The Journal of experimental medicine. 2005; 201(2):233-40.

25. Chang J., Voorhees T.J., Liu Y., Zhao Y., Chang C.H. Interleukin-23 production in dendritic cells is negatively regulated by protein phosphatase $2 \mathrm{~A}$. Proceedings of the National Academy of Sciences of the United States of America. 2010; 107(18):8340-5.

26. Hunter C.A. New IL-12-family members: IL-23 and IL-27, cytokines with divergent functions. Nature reviews Immunology. 2005; 5(7):521-31.

27. Lankford C.S., Frucht D.M. A unique role for IL-23 in promoting cellular immunity. J Leukoc Biol. 2003; 73(1):49-56.

28. Hoeve M.A., Savage N.D., de Boer T., Langenberg D.M., de Waal Malefyt R., Ottenhoff T.H., et al. Divergent effects of IL-12 and IL-23 on the production of IL-17 by human T cells. European journal of immunology. 2006; 36(3):661-70.

29. Karaderi T., Harvey D., Farrar C., Appleton L.H., Stone M.A., Sturrock R.D., et al. Association between the interleukin 23 receptor and ankylosing spondylitis is confirmed by a new UK casecontrol study and meta-analysis of published series. Rheumatology (Oxford, England). 2009; 48(4):386-9.

30. Rahman P., Inman R.D., Gladman D.D., Reeve J.P., Peddle L., Maksymowych W.P. Association of interleukin-23 receptor variants with ankylosing spondylitis. Arthritis and rheumatism. 2008; 58(4):1020-5.

31. Kadi A., Costantino F., Izac B., Leboime A, Said-Nahal R., Garchon H.J., et al. Brief report: the IL23R nonsynonymous polymorphism rs 11209026 is associated with radiographic sacroiliitis in spondyloarthritis. Arthritis and rheumatism. 2013; 65(10):2655-60

32. Rueda B., Orozco G., Raya E., Fernandez-Sueiro J.L., Mulero J., Blanco F.J., et al. The IL23R Arg381GIn non-synonymous polymorphism confers susceptibility to ankylosing spondylitis. Annals of the rheumatic diseases. 2008; 67(10):1451-4.

33. Pimentel-Santos F.M., Ligeiro D., Matos M., Mourao A.F., Sousa E., Pinto P., et al. Association of IL23R and ERAP1 genes with ankylosing spondylitis in a Portuguese population. Clinical and experimental rheumatology. 2009; 27(5):800-6.

34. Szabo M., Safrany E., Pazar B., Melegh B.I., Kisfali P., Poor G., et al. Marked diversity of IL23R gene haplotype variants in rheumatoid arthritis comparing with Crohn's disease and ankylosing spondylitis. Molecular biology reports. 2013; 40(1):359-63.

35. Safrany E., Pazar B., Csongei V., Jaromi L., Polgar N., Sipeky C., et al. Variants of the IL23R gene are associated with ankylosing spondylitis but not with Sjogren syndrome in Hungarian population samples. Scandinavian journal of immunology. 2009; 70(1):68-74.

36. Duan Z., Pan F., Zeng Z., Zhang T., Wang S., Li G., et al. Interleukin-23 receptor genetic polymorphisms and ankylosing spondylitis susceptibility: a meta-analysis. Rheumatology international. 2012; 32(5):1209-14.

37. Lee Y.H., Choi S.J., Ji J.D., Song G.G. Associations between interleukin-23R polymorphisms and ankylosing spondylitis susceptibility: a meta-analysis. Inflammation research: official journal of the European Histamine Research Society [et al]. 2012; 61(2):143-9.

38. Sung I.H., Kim T.H., Bang S.Y., Kim T.J., Lee B., Peddle L., et al. IL-23R polymorphisms in patients with ankylosing spondylitis in Korea. The Journal of rheumatology. 2009; 36(5):1003-5.

39. Davidson S.I., Wu X., Liu Y., Wei M., Danoy P.A., Thomas G., et al. Association of ERAP1, but not IL23R, with ankylosing spondylitis in a Han Chinese population. Arthritis and rheumatism. 2009; 60(11):3263-8.

40. Qian B.P., Jiang J., Ji M.L., Wang B., Yu Y., Qiu Y. Lack of associations between two previously identified susceptible single nucleotide polymorphisms of interleukin-23 receptor gene and ankylosing spondylitis: a replication study in a Chinese Han population. BMC musculoskeletal disorders. 2013; 14:190.

41. Chen C., Zhang X., Li J., Wang Y. Associations of IL-23R polymorphisms with ankylosing spondylitis in East Asian population: 
a new case-control study and a meta-analysis. International journal of immunogenetics. 2012; 39(2):126-30.

42. Davidson S.I., Jiang L., Cortes A., Wu X., Glazov E.A., Donskoi $M$., et al. Brief report: high-throughput sequencing of IL23R reveals a low-frequency, nonsynonymous single-nucleotide polymorphism that is associated with ankylosing spondylitis in a Han Chinese population. Arthritis and rheumatism. 2013; 65(7):1747-52.

43. Dong H., Li Q., Zhang Y., Tan W., Jiang Z. IL23R gene confers susceptibility to ankylosing spondylitis concomitant with uveitis in a Han Chinese population. PloS one. 2013; 8(6):e67505.

44. Wang X., Huang J., Lin Z., Liao Z., Li C., Wei Q., et al. Singlenucleotide polymorphisms and expression of IL23R in Chinese ankylosing spondylitis patients. Rheumatology international. 2010; 30(7):955-9.

45. Duerr R.H., Taylor K.D., Brant S.R., Rioux J.D., Silverberg M.S., Daly M.J., et al. A genome-wide association study identifies IL23R as an inflammatory bowel disease gene. Science (New York, NY). 2006; 314(5804):1461-3.

46. Liu Y., Helms C., Liao W., Zaba L.C., Duan S., Gardner J., et al. A genome-wide association study of psoriasis and psoriatic arthritis identifies new disease loci. PLoS genetics. 2008; 4(3):e1000041.

47. Cargill M., Schrodi S.J., Chang M., Garcia V.E., Brandon R., Callis K.P., et al. A large-scale genetic association study confirms IL12B and leads to the identification of IL23R as psoriasis-risk genes. American journal of human genetics. 2007; 80(2):273-90.

48. Einarsdottir E., Koskinen L.L., Dukes E., Kainu K., Suomela S. Lappalainen M., et al. IL23R in the Swedish, Finnish, Hungarian and Italian populations: association with IBD and psoriasis, and linkage to celiac disease. BMC medical genetics. 2009; 10:8.

49. Catanoso M.G., Boiardi L., Macchioni P., Garagnani P., Sazzini M., De Fanti S., et al. IL-23A, IL-23R, IL-17A and IL-17R polymorphisms in different psoriatic arthritis clinical manifestations in the northern Italian population. Rheumatology international. 2013; 33(5):1165-76.

50. Filer C., Ho P., Smith R.L., Griffiths C., Young H.S., Worthington J., et al. Investigation of association of the IL12B and IL23R genes with psoriatic arthritis. Arthritis and rheumatism. 2008; 58(12):3705-9.

51. Nair R.P., Ruether A., Stuart P.E., Jenisch S., Tejasvi T., Hiremagalore R., et al. Polymorphisms of the IL12B and IL23R genes are associated with psoriasis. The Journal of investigative dermatology. 2008; 128(7):1653-61.

52. Rahman P., Inman R.D., Maksymowych W.P., Reeve J.P., Peddle L., Gladman D.D. Association of interleukin 23 receptor variants with psoriatic arthritis. The Journal of rheumatology. 2009; 36(1):137-40.

53. Di Meglio P., Di Cesare A., Laggner U., Chu C.C., Napolitano L., Villanova F., et al. The IL23R R381Q gene variant protects against immune-mediated diseases by impairing IL-23-induced Th17 effector response in humans. PloS one. 2011; 6(2):e17160.

54. Wong R.H., Wei J.C., Huang C.H., Lee H.S., Chiou S.Y., Lin S.H., et al. Association of IL-12B genetic polymorphism with the susceptibility and disease severity of ankylosing spondylitis. The Journal of rheumatology. 2012; 39(1):135-40.

55. Kenna T.J., Davidson S.I., Duan R., Bradbury L.A., McFarlane J., Smith M., et al. Enrichment of circulating interleukin-17secreting interleukin-23 receptor-positive gamma/delta T cells in patients with active ankylosing spondylitis. Arthritis and rheumatism. 2012; 64(5):1420-9.

56. Chen Z.W. Immune biology of Ag-specific gammadelta T cells in infections. Cellular and molecular life sciences: CMLS. 2011; 68(14):2409-17

57. Taylan A., Sari I., Kozaci D.L., Yuksel A., Bilge S., Yildiz Y., et al. Evaluation of the T helper 17 axis in ankylosing spondylitis. Rheumatology international. 2012; 32(8):2511-5.

58. Mei Y., Pan F., Gao J., Ge R., Duan Z., Zeng Z., et al. Increased serum IL-17 and IL-23 in the patient with ankylosing spondylitis. Clinical rheumatology. 2011; 30(2):269-73.

59. Andersen T., Rasmussen T.K., Hvid M., Holm C.K., Madsen K.J., Jurik A.G., et al. Increased plasma levels of IL-21 and IL-23 in spondyloarthritis are not associated with clinical and MRI findings. Rheumatology international. 2012; 32(2):387-93.

60. Wang X., Lin Z., Wei Q., Jiang Y., Gu J. Expression of IL-23 and IL-17 and effect of IL-23 on IL-17 production in ankylosing spondylitis. Rheumatology international. 2009; 29(11):1343-7.

61. Chen W.S., Chang Y.S., Lin K.C., Lai C.C., Wang S.H., Hsiao K.H., et al. Association of serum interleukin-17 and interleukin-23 levels with disease activity in Chinese patients with ankylosing spondylitis. Journal of the Chinese Medical Association: JCMA. 2012; 75(7):303-8.
62. Xueyi L., Lina C., Zhenbiao W., Qing H., Qiang L., Zhu P. Levels of circulating Th17 cells and regulatory T cells in ankylosing spondylitis patients with an inadequate response to anti-TNF-alpha therapy. Journal of clinical immunology. 2013; 33(1):151-61.

63. Wendling D., Cedoz J.P., Racadot E. Serum and synovial fluid levels of p40 IL12/23 in spondyloarthropathy patients. Clinical rheumatology. 2009; 28(2):187-90.

64. Appel H., Maier R., Bleil J., Hempfing A., Loddenkemper C., Schlichting U., et al. In situ analysis of interleukin-23- and interleukin-12-positive cells in the spine of patients with ankylosing spondylitis. Arthritis and rheumatism. 2013; 65(6):1522-9.

65. Prevosto C., Goodall J.C., Hill Gaston J.S. Cytokine secretion by pathogen recognition receptor-stimulated dendritic cells in rheumatoid arthritis and ankylosing spondylitis. The Journal of rheumatology. 2012; 39(10):1918-28.

66. Ciccia F., Bombardieri M., Principato A., Giardina A., Tripodo C., Porcasi R., et al. Overexpression of interleukin-23, but not interleukin-17, as an immunologic signature of subclinical intestinal inflammation in ankylosing spondylitis. Arthritis and rheumatism. 2009; 60(4):955-65.

67. Tran T.M., Dorris M.L., Satumtira N., Richardson J.A., Hammer R.E., Shang J., et al. Additional human beta2-microglobulin curbs HLA-B27 misfolding and promotes arthritis and spondylitis without colitis in male HLA-B27-transgenic rats. Arthritis and rheumatism. 2006; 54(4):1317-27.

68. Zeng L., Lindstrom M.J., Smith J.A. Ankylosing spondylitis macrophage production of higher levels of interleukin-23 in response to lipopolysaccharide without induction of a significant unfolded protein response. Arthritis and rheumatism. 2011; 63(12):3807-17.

69. Her M., Kavanaugh A. Treatment of spondyloarthropathy: the potential for agents other than TNF inhibitors. Current opinion in rheumatology. 2013; 25(4):455-9.

70. Yeremenko N., Paramarta J.E., Baeten D. The interleukin-23/ interleukin-17 immune axis as a promising new target in the treatment of spondyloarthritis. Current opinion in rheumatology. 2014; 26(4):361-70.

71. Song I.H., Poddubnyy D. New treatment targets in ankylosing spondylitis and other spondyloarthritides. Current opinion in rheumatology. 2011; 23(4):346-51.

72. Poddubnyy D. Axial spondyloarthritis: is there a treatment of choice? Therapeutic advances in musculoskeletal disease. 2013; 5(1):45-54.

73. Poddubnyy D., Hermann K.G., Callhoff J., Listing J., Sieper J. Ustekinumab for the treatment of patients with active ankylosing spondylitis: results of a 28-week, prospective, open-label, proof-ofconcept study (TOPAS). Annals of the rheumatic diseases. 2014; 73(5):817-23.

74. Traczewski P., Rudnicka L. Briakinumab for the treatment of plaque psoriasis. BioDrugs: clinical immunotherapeutics, biopharmaceuticals and gene therapy. 2012; 26(1):9-20.

75. Baeten D., Baraliakos X., Braun J., Sieper J., Emery P., van der Heijde D., et al. Anti-interleukin-17A monoclonal antibody secukinumab in treatment of ankylosing spondylitis: a randomised, double-blind, placebo-controlled trial. Lancet. 2013; 382(9906):1705-13.

76. Baeten D. B.J., Baraliakos X., et al. Secukinumab, a monoclonal antibody to interleukin-17A, significantly improves signs and symptoms of active ankylosing spondylitis: results of a 52-week phase 3 randomized placebo-controlled trial with intravenous loading and subcutaneous maintenance dosing. ACR /ARHP Annual Meeting; Boston, MA, USA 2014.

77. Sanford M., McKeage K. Secukinumab: First Global Approval. Drugs. 2015.

78. Busquets-Perez N., Marzo-Ortega H., Emery P. Emerging drugs for axial spondyloarthritis including ankylosing spondylitis. Expert opinion on emerging drugs. 2013; 18(1):71-86.

79. McGeachy M.J., Chen Y., Tato C.M., Laurence A., Joyce-Shaikh B., Blumenschein W.M., et al. The interleukin 23 receptor is essential for the terminal differentiation of interleukin 17-producing effector T helper cells in vivo. Nature immunology. 2009; 10(3):314-24.

80. Cornelissen F., Mus A.M., Asmawidjaja P.S., van Hamburg J.P., Tocker J., Lubberts E. Interleukin-23 is critical for full-blown expression of a non-autoimmune destructive arthritis and regulates interleukin-17A and RORgammat in gammadelta T cells. Arthritis research \& therapy. 2009; 11(6):R194.

81. Sutton C.E., Lalor S.J., Sweeney C.M., Brereton C.F,. Lavelle E.C., Mills K.H. Interleukin-1 and IL-23 induce innate IL-17 production from gammadelta T cells, amplifying Th17 responses and autoimmunity. Immunity. 2009; 31(2):331-41. 